\title{
Inflammatory Breast Diseases during Lactation: Milk Stasis, Puerperal Mastitis, Abscesses of the Breast, and Malignant Tumors - Current and Evidence-Based Strategies for Diagnosis and Therapy
}

\author{
Michael Abou-Dakn ${ }^{\mathrm{a}}$ Anna Richardt ${ }^{\mathrm{a}}$ Ute Schaefer-Graf ${ }^{\mathrm{a}}$ Achim Wöckel ${ }^{\mathrm{b}}$ \\ ${ }^{a}$ St. Joseph-Hospital Berlin, Academic Hospital of the Charité, University Medicine Berlin, \\ ${ }^{\mathrm{b}}$ Department of Obstetrics and Gynecology, University Hospital UIm, Germany
}

\section{Key Words}

Breastfeeding - Milk stasis - Puerperal mastitis .

Puerperal abscess

\section{Summary}

Background: Breast diseases during the lactation period are of high importance because they can be an essential cause for early cessation of breastfeeding. Methods: To provide a comprehensive overview on the current recommendations of diagnostics and therapies, a systematic literature research was performed on a variety of online medical databases. Results: The primary aim of all therapy is a quick reduction of pain to allow continued breastfeeding. Each particular form of breast disease requires a specific therapy. These can range from conservative measures to antibiotics and surgical procedures. All therapeutic measures, including pharmacotherapy, are normally not an indication for cessation of breastfeeding. Conclusion: Because the majority of breast diseases during the postnatal period occur only after the women have left the maternity clinics, all involved healthcare workers should educate women especially on preventive measures.

\section{Introduction}

The WHO recommends exclusive breastfeeding for a period of 6 months. Many studies have affirmed that a history of breastfeeding is associated with a reduced risk of many dis-

\author{
Schlüsselwörter \\ Stillen · Brustwarzen, wunde - Milchstau - Mastitis · \\ Abszess
}

\section{Zusammenfassung}

Hintergrund: Brusterkrankungen der Stillzeit (wunde Brustwarzen, Milchstau, Mastitis, Abszess) sind sehr bedeutend, da sie als wichtigster Grund für das frühzeitige Abstillen gelten. Methoden: Um eine Übersicht zu aktuellen Empfehlungen der Diagnostik und Therapie geben zu können, wurde eine systematische Literaturrecherche in verschiedenen medizinischen Datenbanken durchgeführt. Ergebnisse: Primäres Ziel der Therapie ist es, die Beschwerden rasch zu reduzieren, um ein Weiterstillen zu ermöglichen. Die jeweilige Form der Brusterkrankung bedarf einer spezifischen Therapie. Diese reicht von konservativen physikalischen Maßnahmen über antibiotische Therapien bis hin zu operativen Eingriffen bei einem Abszess. Die therapeutischen Maßnahmen, aber auch die medikamentöse Therapie, stellen in der Regel keine Indikation zum Abstillen dar. Schlussfolgerung: Da der Großteil der Erkrankungen erst im Wochenbett außerhalb der Betreuung der Geburtsklinik auftritt, sollten die beteiligten Berufsgruppen die Frauen vor allem auch über präventive Maßnahmen aufklären.

eases in infants and mothers [1]. Problems and diseases of the female breast caused by breastfeeding are the most common reason for premature cessation of breastfeeding [2] and occur with a prevalence of up to $50 \%$ in breastfeeding mothers [3-5]. Breast diseases during the lactation period include

\section{KARGER}

Fax +497614520714

Information@Karger.de

www.karger.com (c) 2010 S. Karger GmbH, Freiburg

www.karger.com/brc 
mainly problems of the nipples, like abrasions, cracks and ulcerations, plus milk stasis, puerperal mastitis and abscesses. Some of these different manifestations are related to physiological circumstances and limit, especially in the first weeks postpartum, the duration of the lactation period, although they can occur during the whole period of lactation [6].

Injuries of the nipples can be caused by having the child not correctly attached to the breast [5]. The risk of weaning will be 14.7 times higher when the mothers are in pain while breastfeeding [2]. Pain can lead to ineffective milk removal, a consequence of which can be milk stasis. Other reasons for milk stasis can be insufficient breastfeeding techniques, e.g. no emptying of all four quadrants and too short or too rare breastfeeding sessions. Further pressure on single milk ducts can lead to blockage of the proximal milk ducts. This can be caused by pressure on the breast (e.g., by a tight bra or a car seatbelt) [7].

In over $30 \%$ of all mothers, skin damages of the nipples and the areola can be found in the first days postpartum. On these abrasions, cracks and ulcerations, a secondary colonization with pathogens can occur and may lead to an infection [3]. In most of the cases, the transmission of pathogens does not occur through the mother, but often through medical staff and relatives. Poor hand hygiene leads to an infection of the nipple or the throat of the baby and can then cause a secondary mastitis [8-10]. The mother is rarely the transmitter of the pathogens because her specific antibodies have been transmitted already prenatally to the baby and she secretes the antibodies through her breast milk [11]. Spreading of a puerperal mastitis into connective and adipose tissue can cause the formation of abscesses.

Because of the different clinical manifestations of breast diseases connected to lactation, a wide range of professional groups may be confronted with them [12]. To provide a comprehensive evidence-based and up-to-date overview on prevention, diagnostics and therapeutic approaches, we performed a systematic literature research. The aim of this review was to present practicable instructions for the diagnosis and therapy of breast diseases during lactation.

\section{Methods}

\section{Retrieval Strategies}

The systematic literature research was performed on the following databases: Medline, Cinhal, Embase, Biosis, Cochrane. The search terms used were: milk stasis, puerperal mastitis, and puerperal abscess.

\section{Inclusion and Exclusion Criteria}

In the first search, all publications in German and English language since 1990 were included.

The selection and inclusion of studies in this review were carried out according to relevance (reference to diagnostics and therapies of lactation-caused breast diseases) and methodical criteria (studies with high level of evidence: prospective or retrospective cohort studies with sufficient numbers of cases and little risk of bias for diagnostic strategies; pro- spective intervention studies for therapeutic strategies). Furthermore, already existing consensus decisions and guidelines were included in the research and analyzed. Excluded were studies lacking relevance and publications using methods of lower statistical significance (e.g. case reports, case series and expert opinions). Additionally, the bibliographies of all publications were analyzed to gain further information about relevant publications. The terms 'mastitis', 'milk stasis', 'puerperal abscess', 'diagnosis', and 'therapy' were used as keywords.

\section{Results}

In our systematic literature research, we were able to select 16 studies that gave recommendations for the diagnosis and therapy of breast diseases during lactation.

\section{Diagnostics and Additional Examinations}

It is difficult to differentiate between milk stasis and mastitis just from their clinical appearances. The typical signs of infection, like fever, redness of the infected area and profound systemic illness, occur in both cases. For the diagnosis of milk stasis or mastitis, normally no further diagnostic procedures are needed. However, in the case of unusually severe symptoms of infection (massive hyperthermia, redness, fever $>38.5^{\circ} \mathrm{C}$, profound systemic illness), an ultrasound examination of the breast should be performed additionally, to be able to treat complications (like abscesses) at an early stage. The whole breast should hereby be examined because abscesses often spread into neighboring tissue [13]. The WHO additionally recommends undertaking a breast milk culture and sensitivity testing in cases where there is no clinical improvement in acute mastitis within $48 \mathrm{~h}$ after antibiotic therapy. The same recommendations apply to cases of recurrent mastitis, hospital-acquired mastitis and allergic intolerance to usual therapeutic antibiotics [14]. To obtain a milk sample, the breast should be expressed manually. After discharge of the first portion - to avoid contamination with pathogens of the skin flora - the milk should be collected in a test tube for urine samples. An initial disinfection of the areola can additionally reduce the contamination with skin flora and help prevent false-positive results.

\section{Therapeutic Strategies}

\section{Milk Stasis and Mastitis}

Besides a quick reduction of clinical symptoms, the primary aim of all therapeutic measures should therefore be to mechanically clear the blockage and stasis. Cessation of breastfeeding in this phase should be avoided because it can in turn reinforce the stasis. If this cannot be achieved by normal breastfeeding or manual expression, the milk should be pump-expressed. The woman should be especially informed that the affected breast needs to be included and that she should start breastfeeding sessions with the affected breast 
Table 1. Antibiotics for the treatment of puerperal mastitis

\begin{tabular}{llll}
\hline Group & Drug & Dose $(\mathrm{mg} /$ day $)$ & Comment \\
\hline Penicillin & amoxicillin + clavulanic acid & $3 \times 500$ & observe infant for diarrhea or thrush \\
& flucloxacillin & $3 \times 1,000$ & observe infant for diarrhea or thrush \\
Cephalosporin & cephalexin & $3 \times 1,000$ & observe infant for diarrhea or thrush \\
& cefotaxim & $2 \times 1,000$ & observe infant for diarrhea or thrush \\
\multirow{3}{*}{ Macrolide } & cefuroxim & $3 \times 1,500$ & observe infant for diarrhea or thrush \\
Other & clarithromycin & $2-4 \times 500$ & observe infant for diarrhea or thrush; cave: icterus \\
& clindamycin & $3 \times 300$ & observe infant for diarrhea or thrush; bloody stool \\
\hline
\end{tabular}

[7]. If pain prohibits letdown, sides should be changed, so feeding may begin on the unaffected breast, switching to the affected breast as soon as letdown is achieved. Additionally, the infant can be positioned at the breast with the chin or nose pointing towards the blockage, which will help drain the area. These 'massages' can be continued in the feeding intervals, whereby massaging should be directed towards the nipples to additionally express concentrated secretion from the milk ducts.

Immediately after feeding, expressing the milk by hand or pump may reduce the risk of a new blockage and mastitis or abscesses [6]. There is no evidence that continued breastfeeding in case of milk stasis, mastitis or abscesses harms the newborn [7]. One of the rare exceptions is acute bilateral puerperal mastitis which is caused by more aggressive pathogens (e.g. $\beta$-hemolytic streptococcus group B). In these rare cases, breastfeeding should be suspended for 1-2 days while an adequate antibiotic therapy is performed. During this pause, the milk should be pump-expressed and discarded. A simultaneous therapy of the newborn is often necessary. After fever and clinical symptoms have resolved, breastfeeding can be continued [15].

Supportive measures can help regulate the milk flow in cases of milk stasis and puerperal mastitis. Local application of heat prior to feeding helps stimulate the milk flow, while application of cold after feeding or expressing milk from the breasts can reduce milk production and therefore symptoms like pain and edema.

Hospital admission is only indicated in cases of poor general condition in which the woman is severely ill.

In case of milk stasis, conservative therapeutic measures should be tried for $24 \mathrm{~h}$. If the symptoms do not improve, or in case of severe illness, the application of antibiotics becomes necessary [16]. In theory, it is possible to differentiate between bacterial mastitis and milk stasis by quantifying the leucocytes and pathogenic bacteria in the breast milk (> 104 colony-forming units $/ \mathrm{ml}$ and $>106$ leucocytes $/ \mathrm{ml}$ milk). In practice, however, infectious mastitis is suspected and treated pharmacologically if, after $24 \mathrm{~h}$ of conservative measures (as described above), no improvement of the clinical symptoms took place [6]. According to a Swedish trial, no relevant differences regarding clinical and attendant symptoms can be found. Merely the number of leucocytes in maternal serum was higher in the group with proven bacterial mastitis [17].
The most common pathogens in infective mastitis are penicillin-resistant Staphylococcus aureus, less commonly Streptococcus and Escherichia coli. Therefore, penicillinase-resistant penicillins such as dicloxacillin or flucloxacillin $(500 \mathrm{mg}$, 4 times per day) are the preferred therapy. First-generation cephalosporins are also accepted as first-line therapy. Cephalexin, for example, can be used in cases of penicillin intolerance, whereas in cases of manifest penicillin allergy clindamycin should be used. Dicloxacillin seems to have fewer hepatic adverse effects than flucloxacillin [16]. On the other hand, it tends to cause phlebitis if applied intravenously; so in milder cases it should be preferably given orally. Although an application is often recommended for a period of 14 days, there is currently no evidence from controlled prospective trials regarding the appropriate duration of antibiotic therapy [18] (table 1). In women with persisting symptoms, a breast milk culture and inquiry of antibiotic resistances should be conducted because of the increase of penicillinase-resistant, methicillin-resistant (MRSA) and oxacillin-resistant S. aureus (ORSA) [19].

\section{Abscesses and Complications}

An improvement of the clinical symptoms should be noticeable at 24 to latest $48 \mathrm{~h}$ after antibiotic therapy has begun. In persisting or recurrent cases, an antibiotic resistance or other differential diagnosis has to be considered. Abscesses as well as inflammatory and ductal carcinoma of the mamma could be the cause for the disorders [20].

In cases of local indurations, redness and hyperthermia, an abscess may develop in about 3\% of women with mastitis [21]. Systemic symptoms like fever may not be present. An ultrasound examination of the breast and the identification of hypoechoic areas lead to the diagnosis of abscesses. The collected fluids need to be drained and rinsed under ultrasound guidance or drained surgically. Under general anesthesia, an incision and, if necessary, placement of a drain and counter-incision is carried out in order to drain and clear the abscess cavity. The wound may need to be rinsed daily until secretion decreases and seems to be clear.

Antibiotics are not necessary if the abscess cavity was opened and cleared widely. If possible, the incision should not be made in the areola region so as to allow continued breastfeeding. Normally, the abscess cavity granulates and closes without complications within 4 weeks. Compared to surgical 
intervention, needle aspiration is cheaper, less painful and allows a faster convalescence [22]. Therefore, surgical drainage should only be favored if the abscess is very large or if there are multiple abscesses. However, currently no recommendations exist regarding different aspiration techniques, due to a lack of prospective trials. Up to now, it is not clear whether serial aspirations have an effect equivalent to a single aspiration followed by placement of a drain. In any case, pathogenic bacteria and resistances should be detected from the milk as well as directly from the purulent material, because of the increase of MRSA [9]. A course of antibiotic should follow after drainage or aspiration of the abscess. Breastfeeding should be continued to further relieve the breast tissue. Taking the appropriate antibiotics into account, the milk can still be fed to the infant. After local anesthesia and careful disinfection of the area, aspiration should be performed under ultrasound guidance with a 1.1-1.9 mm $80 \mathrm{~mm}$ needle (some authors also use a probe or drain). If the abscess fluids are highly viscous and tough-flowing, rinsing with physiological saline (and if necessary antibiotic solutions) can be helpful. Iodine solutions should not be used anymore because of the protein effect (flocculation of iodine-protein bonds). The injection site should possibly be far from the areola; however, the distance between abscess and skin should not be too far because of the danger of bacterial dissemination. The aspiration should be repeated daily until the abscess caliber gets too small for safe puncture: Normally, a diameter of less than $4 \mathrm{~mm}$ cannot be punctured anymore. By following this procedure, surgical abscess drainage can be avoided in $70 \%$ of cases, according to our own trials. On average, serial aspirations (2-9 times) are necessary. The fundamental advantage of abscess aspiration is the reduced feeling of illness for the woman because hospital admission is normally not necessary. The disadvantage is the ineffective analgesia in the acute state [20].

\section{Discussion and Conclusion}

The current literature review shows that there is insufficient evidence to confirm or refute the effectiveness of different therapies for the treatment of breast diseases during lactation.

There is an urgent need to conduct high-quality, doubleblinded clinical trials to determine whether intervention should be used in this common postpartum condition. Because of the known health advantages of breastfeeding for mother and child, it is ethically not acceptable to randomize breastfeeding [23, 24]. Even under study conditions women should be encouraged to breastfeed exclusively. Therefore, as a compromise, studies blinded to the effect should be performed, or data from bigger register and cohort studies with subgroups that do not breastfeed should be evaluated. A methodical limitation of our review is that, because of the different study designs of the selected literature, a direct comparison between individual parameters was not possible. Because of the limitations of existing studies, our recommendations for clinical routine are based mainly on studies with rather low evidence level.

Inflammatory breast diseases during lactation can usually be treated conservatively and in an outpatient setting. The majority of breastfeeding complications and diseases occur only after hospital discharge when there is no intensive care through specialized health workers anymore. Therefore, it is of great importance that all involved professional groups (gynecologists, dermatologists, pediatricians, lactation consultants and midwives) educate women early enough on prevention of these inflammatory complications.

The following recommendations or clinical algorithms can be deduced from the current existing studies:

- If milk stasis or mastitis is suspected, an ultrasound should be performed to recognize early abscesses. Milk stasis and mastitis cannot be differentiated clearly just from their clinical appearances.

- According to current data there is no indication for weaning in case of milk stasis, puerperal mastitis (except bilateral mastitis) and abscesses, even if this is the mother's will. Ineffective milk removal even aggravates the symptoms.

- Initially, conservative therapeutic measures should be tried for at least $24 \mathrm{~h}$ (antipyretics, physical rest, substitution of liquids, frequent breastfeeding, and emptying of the affected breast).

- If an improvement cannot be achieved by conservative measures, mastitis must be assumed. In this case, antibiotics should be given.

- If after another $24 \mathrm{~h}$ no therapeutic success can be found, the antibiotics should be changed.

- In case of persisting symptoms, an abscess must be excluded. Current data shows that needle aspiration should be favored over surgical intervention. (When indicated, malignant tumors can be excluded by biopsy).

- Special emphasis should be put on preventative measures: All women should be made aware to regularly check their breasts for lumps, redness or painful areas. Increased breastfeeding frequency, milk removal by hand or pump and massage of lumpy or red areas preventively protects from mastitis and abscesses if signs of milk stasis are already present. Because fatigue and stress are often relevant triggers to mastitis, undue exposure to stress should be avoided postpartum [12]. Because of the increasing prevalence of MRSA and its close association with inflammatory breast diseases, thorough education on hand hygiene needs to be given [25]. It is important to focus on the motivation of the women and their relatives so that they do not cease breastfeeding too early and thereby worsen the symptoms.

\section{Conflict of Interest}

The authors of this manuscript have no conflict of interest. 


\section{References}

1 Ip S, Chung M, Raman G, Chew P, Magula N, Devine D, Trikalinos T, Lau J: Breastfeeding and maternal and infant health outcomes in developed countries. Evid Rep Technol Assess 2007;13:1-186.

-2 Schwartz K, D'Arcy HJ, Gillespie B, Bobo J, Longeway M, Foxman B: Factors associated with weaning in the first 3 months postpartum. J Fam Pract 2002;51:439-444.

>3 Foxman B, D'Arcy H, Gillespie B, Bobo JK Schwartz K: Lactation mastitis: Occurrence and medical management among 946 breastfeeding women in the United States. Am J Epidemiol 2002; 155:103-114.

4 Kinlay JR, O'Connell DL, Kinlay S: Incidence of mastitis in breastfeeding women during the six months after delivery: A prospective cohort study. Med J Aust 1998;169:310-312.

$\checkmark 5$ Waldenstrom U, Aarts C: Duration of breastfeeding and breastfeeding problems in relation to length of postpartum stay: A longitudinal cohort study of a national Swedish sample. Acta Paediatr 2004;93: 669-676.

6 Abou-Dakn M, Wöckel A: Verstärkter initialer Milcheinschuss, Milchstau, Mastitis puerperalis und Abszess der laktierenden Brust. Geburtshilfe Frauenheilkd 2007;67:1166-1169.

7 ABM clinical protocol 4: mastitis. Revision, May 2008. Breastfeed Med 2008;3:177-180.

8 Amir LH, Garland SM, Lumley J: A case-control study of mastitis: Nasal carriage of Staphylococcus aureus. BMC Fam Pract 2006;7:57.
Peters J: Mastitis puerperalis - causes and therapy. Zentralbl Gynakol 2004;126:73-76.

10 Peters F, Flick-Fillies D, Ebel S: Hand disinfection as the central factor in prevention of puerperal mastitis. Clinical study and results of a survey. Geburtshilfe Frauenheilkd 1992;52:117-120.

11 Hanson LA, Korotkova M, Lundin S, Haversen L, Silfverdal SA, Mattsby-Baltzer I, Strandvik B, Telemo E: The transfer of immunity from mother to child. Ann N Y Acad Sci 2003;987:199-206.

12 Wockel A, Abou-Dakn M, Beggel A, Arck P: Inflammatory breast diseases during lactation: Health effects on the newborn - a literature review. Mediators Inflamm 2008;2008:298760.

13 Amir LH, Forster D, McLachlan H, Lumley J: Incidence of breast abscess in lactating women: Report from an Australian cohort. BJOG 2004;111:13781381.

14 WHO: Mastitis - causes and management. Geneva, WHO/FCH/CAH/0013, 2000, pp 1-45.

15 Kotiw M, Zhang GW, Daggard G, Reiss-Levy E, Tapsall JW, Numa A: Late-onset and recurrent neonatal group B streptococcal disease associated with breast-milk transmission. Pediatr Dev Pathol 2003;6:251-256.

16 Jahanfar S, Ng CJ, Teng CL: Antibiotics for mastitis in breastfeeding women. Cochrane Database Syst Rev 2009:CD005458.
7 Osterman KL, Rahm VA: Lactation mastitis: Bacterial cultivation of breast milk, symptoms, treatment, and outcome. J Hum Lact 2000;16:297-302.

18 Lawrence RA: Mastitis while breastfeeding: Old theories and new evidence. Am J Epidemiol 2002; 155:115-116.

19 Reddy P, Qi C, Zembower T, Noskin GA, Bolon M: Postpartum mastitis and community-acquired methicillin-resistant Staphylococcus aureus. Emerg Infect Dis 2007;13:298-301.

20 Abou-Dakn M, Nehlsen E, Wöckel A: Nicht abstillen bei Mastitis oder Milchstau. DHZ 2005:55-59.

21 Amir LH, Forster DA, Lumley J, McLachlan H: A descriptive study of mastitis in Australian breastfeeding women: Incidence and determinants. BMC Public Health 2007;7:62.

22 Strauss A, Middendorf K, Muller-Egloff S, Heer IM, Untch M, Bauerfeind I: Sonographically guided percutaneous needle aspiration of breast abscesses - a minimal-invasive alternative to surgical incision. Ultraschall Med 2003;24:393-398.

23 Jones G, Steketee RW, Black RE, Bhutta ZA, Morris SS: How many child deaths can we prevent this year? Lancet 2003;362:65-71.

24 Labbok MH: Effects of breastfeeding on the mother Pediatr Clin North Am 2001;48:143-158.

25 Collignon PJ, Grayson ML, Johnson PD: Methicillin-resistant Staphylococcus aureus in hospitals: Time for a culture change. Med J Aust 2007;187:4-5. 